\title{
Conhecimento dos cirurgiões-dentistas do município de Capão da Canoa sobre o atendimento a pacientes oncológicos
}

\section{Knowledge of dental surgeons from the city of Capão da Canoa on the care for cancer patients}

\author{
Luara Zanini* \\ Marcylene Arruda Braz** \\ Naiara Leites Larentis ${ }^{* * *}$ \\ Julia Itzel Acosta Moreno Vinholes ${ }^{* * *}$
}

\section{Resumo}

Objetivo: avaliar, por meio de um questionário, o nível de conhecimento do cirurgião-dentista sobre o atendimento a pacientes oncológicos. Sujeitos e método: foram distribuídos 51 questionários no município de Capão da Canoa, RS, sendo que 23 foram respondidos. Resultados: a maioria dos profissionais usa clorexidina $0,12 \%$ como antisséptico bucal durante o atendimento a pacientes em tratamento de quimioterapia e/ou radioterapia, e não faria exodontia de terceiros molares e dentes parcialmente erupcionados nesses pacientes. Ainda, 52,17\% não indicariam colocação de implantes após a terapia radioterápica, os demais indicariam, no mínimo, após um ano do tratamento. Para a realização de exodontias e evitar a osteorradionecrose, 21,73\% só fariam após 6 meses, 39,13\% após 1 ano e o restante após 3 anos ou mais. Para infecções fúngicas, o medicamento mais apontado foi a Nistatina. No caso de infecções virais, a maioria não respondeu. Dos entrevistados, 43,47\% não saberiam fazer o diagnóstico de mucosite, já quanto ao seu tratamento, a maioria não respondeu. A xerostomia foi a complicação bucal mais apontada entre os problemas que esses pacientes podem apresentar, sendo as infecções também bastante citadas. Para que essas alterações possam ser diagnosticadas precocemente e se saiba como agir durante o tratamento dos pacientes oncológicos, os entrevistados responderam que é necessário verificar as condições bucais do paciente antes do início do tratamento radioterápico e fazer contato com o médico responsável para saber do estado de saúde geral do paciente.
Conclusão: muitos dentistas ainda têm dúvidas sobre $o$ atendimento a pacientes oncológicos, não sabendo realizar um protocolo para o atendimento desses.

Palavras-chave: Inquéritos e questionários. Neoplasias. Odontologia. Oncologia.

\section{Introdução}

Além dos efeitos terapêuticos da radioterapia para o tratamento das neoplasias malignas, algumas complicações específicas podem ser ocasionadas quando é envolvido o campo cérvico-facial, como cárie e mucosite radioinduzidas, candidíase, osteorradionecrose, xerostomia, limitação do grau de abertura bucal, periodontite, diminuição da qualidade da função mastigatória e disgeusia ${ }^{1-8}$.

A quimioterapia é um tratamento sistêmico que utiliza medicamentos para combater as neoplasias malignas. As drogas misturam-se com o sangue e são levadas a todas as partes do corpo, destruindo as células malignas que estão formando o tumor e impedindo, também, que elas se espalhem pelo corpo $^{9}$. Como na radioterapia, os tratamentos quimioterápicos também podem atingir células saudáveis dos tecidos bucais9. E quanto mais jovem for o paciente, maiores são as chances de desenvolver 
lesões bucais durante o tratamento quimioterápico, devido ao índice mitótico elevado das células da mucosa bucal, que pode ser considerado um fator adjuvante $^{1}$. Em torno de duas semanas após o início da quimioterapia, a quantidade de leucócitos é reduzida para um nível extremamente baixo. $O$ efeito da mielossupressão na cavidade bucal é a gengivite marginal, podendo ocorrer também infecções leves. Se houver uma neutropenia severa e prolongada, infecções graves podem se desenvolver ${ }^{10}$.

Assim, o tratamento odontológico antes do tratamento do câncer é considerado uma medida preventiva que tende a diminuir os efeitos colaterais ${ }^{11}$. É realizado um rigoroso exame clínico antes de iniciar o tratamento oncológico, devendo-se analisar minuciosamente as condições dentais e periodontais do paciente $\mathrm{e}^{5,12,13}$. Os processos inflamatórios e infecciosos devem ser extintos e controlados. Paralelamente, o paciente deve adquirir hábitos de higiene bucal, de forma que ele possa controlar a placa bacteriana durante e após o tratamento do câncer ${ }^{11}$. Por isso, um bom relacionamento entre o cirurgião-dentista e a equipe oncológica é de extrema importância ${ }^{14}$, na tentativa de minimizar o desconforto do paciente ocasionado pelas sequelas dos tratamentos quimioterápico e radioterápico.

Em vista disso, o objetivo deste trabalho foi avaliar, por meio de um questionário, o nível de conhecimento do cirurgião-dentista sobre os efeitos secundários do tratamento oncológico.

\section{Sujeitos e método}

O presente estudo foi aprovado pelo Comitê de Ética em Pesquisa de Seres Humanos e Animais da Universidade Luterana do Brasil sob o parecer de número CAAE 08107012.3.0000.5349.

$\mathrm{O}$ instrumento de análise foi um questionário autoexplicativo contendo questões sobre o perfil do profissional e das condutas clínicas adotadas pelo cirurgião-dentista durante o atendimento odontológico de pacientes oncológicos. O questionário foi elaborado com questões fechadas e abertas. Foram distribuídos 63 questionários, sendo 12 aos dentistas da cidade de Torres, RS, e 51 em Capão da Canoa, RS. Dos questionários entregues em Torres, apenas 9 foram devolvidos, já em Capão da Canoa, 23 questionários foram respondidos. Todos os questionários foram entregues pessoalmente pela pesquisadora, juntamente com o termo de consentimento livre e esclarecido.

Os participantes foram informados dos objetivos da pesquisa e de sua participação, sendo-lhes asseguradas a privacidade e a confidencialidade de suas identidades. Foi solicitado que respondessem com seus próprios conhecimentos, sem consulta de livros e meios eletrônicos, a fim de não interferir nos resultados da pesquisa.
Como os questionários entregues no município de Torres foram entregues com grande parte das respostas incompletas, decidiu-se por utilizar apenas a amostra do município de Capão da Canoa. Após recolher os questionários, foi realizada a análise dos resultados, sendo agrupadas as respostas por categorias. Posteriormente à análise das respostas, essas foram tabuladas e submetidas à análise por porcentagem.

\section{Resultados}

Participaram da pesquisa 23 cirurgiões-dentistas. As respostas das questões mais pertinentes ao estudo estão expostas a seguir.

Durante $o$ atendimento odontológico de pacientes em tratamento de quimioterapia e/ou radioterapia, a maioria $(78,26 \%)$ dos profissionais responderam que usam clorexidina $0,12 \%$ como antisséptico bucal (Figura 1).

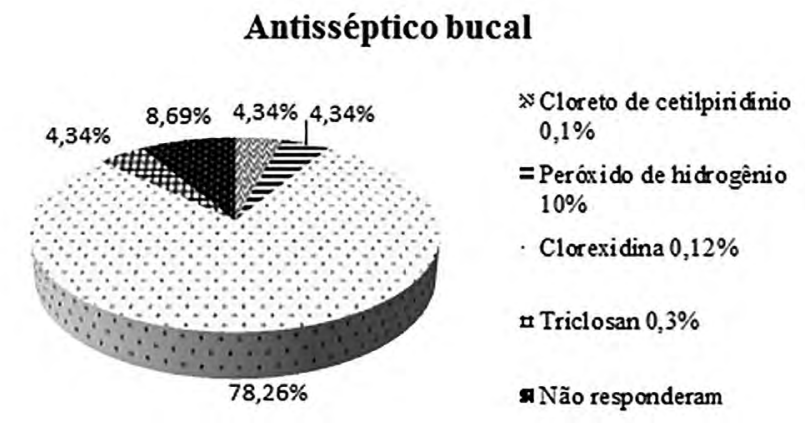

Figura 1 - Resposta à questão sobre o uso de antisséptico bucal para paciente em tratamento quimioterápico/radioterápico

Fonte: elaboração dos autores.

Sobre a exodontia de terceiros molares impactados, $86,96 \%$ responderam que não fariam e $13,04 \%$ que fariam. Em dentes parcialmente erupcionados, $78,26 \%$ não indicariam a exodontia e $8,69 \%$ fariam a exodontia. Tabela 1 - Resposta as questões sobre a indicação de exodontia de
terceiros molares impactados e dentes parcialmente erup-
cionados

\begin{tabular}{l|r|r|r}
\cline { 2 - 4 } & \multicolumn{3}{c}{ Exodontia } \\
\cline { 2 - 4 } & $\begin{array}{c}\text { Não } \\
\text { fariam }\end{array}$ & Fariam & $\begin{array}{c}\text { Não } \\
\text { responderam }\end{array}$ \\
\hline Molares impactados & $86,96 \%$ & $13,04 \%$ & $0 \%$ \\
\hline $\begin{array}{l}\text { Dentes parcialmente } \\
\text { erupcionados }\end{array}$ & $78,26 \%$ & $8,69 \%$ & $13,04 \%$ \\
\hline
\end{tabular}

Fonte: elaboração dos autores.

Quanto à periodicidade das consultas de manutenção, a maioria $(43,47 \%)$ dos entrevistados relatou que faria a cada 3 meses ou mais, seguidos por aqueles que fariam a cada 15 dias $(17,39 \%)$. As demais porcentagens de respostas estão expostas na Tabela 2. 
Tabela 2 - Respostas sobre a periodicidade das consultas

\begin{tabular}{l|c}
\hline \multicolumn{2}{l}{$\begin{array}{c}\text { Após o tratamento oncológico, qual seria a periodicidade } \\
\text { das consultas de manutenção? }\end{array}$} \\
\hline 1 vez por semana & $0 \%$ \\
A cada 15 dias & $17,39 \%$ \\
A cada 30 dias & $13,04 \%$ \\
A cada 3 ou 4 meses & $43,47 \%$ \\
A cada 6 meses & $17,39 \%$ \\
Não responderam & $8,69 \%$ \\
\hline
\end{tabular}

Fonte: elaboração dos autores.

Em relação à colocação de implantes, $52,17 \%$ não indicariam após a terapia radioterápica em região de cabeça e pescoço e os outros fariam, no mínimo, após 1 ano (Tabela 3).

Tabela 3 - Respostas sobre a indicação de implantes

\begin{tabular}{l|r}
\hline $\begin{array}{l}\text { Você indicaria a colocação de implantes quanto tempo } \\
\text { após o tratamento? }\end{array}$ & $0 \%$ \\
\hline 1 mês & $0 \%$ \\
6 meses & $34,78 \%$ \\
1 ano & $0 \%$ \\
3 anos & $4,34 \%$ \\
5 anos & $52,17 \%$ \\
Não indicariam a colocação de implantes & $8,69 \%$ \\
Não responderam & \\
\hline
\end{tabular}

Fonte: elaboração dos autores.

Sobre o tempo ideal para realizar exodontias e evitar a osteorradionecrose, 21,73\% relataram que somente após 6 meses, 39,13\% após 1 ano e o restante 3 anos ou mais (Figura 2).

\section{Exodontias após tratamento oncológico}
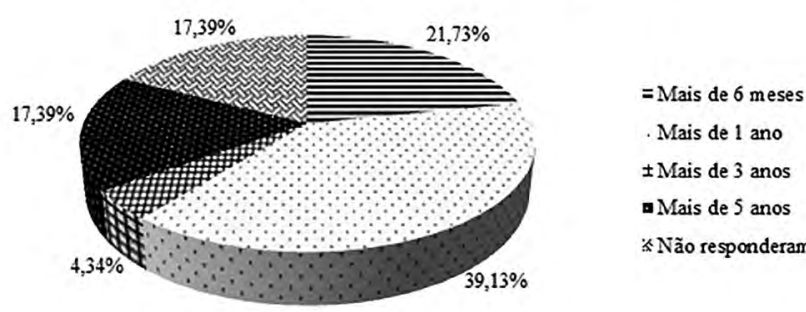

Figura 2 - Tempo ideal para realizar exodontias Fonte: elaboração dos autores.

Quando perguntados sobre os cuidados que teriam com próteses realizadas antes ou após a radioterapia, a maioria $(43,47 \%)$ respondeu que faria próteses bem adaptadas, polidas e com alívios para não lesar a mucosa.
Tabela 4 - Respostas sobre os cuidados com os tratamentos protéticos

Quais cuidados você teria em relação às próteses realizadas em pacientes edêntulos pouco antes ou logo após a radioterapia?

\section{Não responderam}

$8,69 \%$

Não usariam próteses durante o tratamento

$13,04 \%$

Instrução de higiene bucal e das próteses

$30,43 \%$

Próteses bem adaptadas, polidas e com alí-

$43,47 \%$

vios para não lesar a mucosa

Manipular saliva artificial

Tratamento igual ao de pacientes que não estejam fazendo quimioterapia e/ou radioterapia

Não realizariam esse procedimento Fonte: elaboração dos autores.

Entre os medicamentos para infecções fúngicas, a Nistatina foi a mais apontada. No caso de infecções virais, a maioria não respondeu a pergunta, mas os dentistas que responderam indicaram Aciclovir (Tabela 5).

Tabela 5 - Medicamentos indicados para infecções fúngicas e virais

\begin{tabular}{|c|c|c|}
\hline \multicolumn{3}{|c|}{ Medicamento indicado } \\
\hline \multirow{8}{*}{$\begin{array}{l}\text { Infecções } \\
\text { fúngicas }\end{array}$} & Não responderam & $13,04 \%$ \\
\hline & Nistatina & $65,21 \%$ \\
\hline & Fluconazol & $4,34 \%$ \\
\hline & Dacktarin gel & $8,69 \%$ \\
\hline & Metronidazol & $4,34 \%$ \\
\hline & "Medicamentos antifúngicos" & $4,34 \%$ \\
\hline & Sinvastatina & $4,34 \%$ \\
\hline & Cetoconazol & $8,69 \%$ \\
\hline \multirow{6}{*}{$\begin{array}{l}\text { Infecções } \\
\text { virais }\end{array}$} & Não responderam & $34,78 \%$ \\
\hline & Depende do vírus & $8,69 \%$ \\
\hline & Aciclovir & $30,43 \%$ \\
\hline & Antibióticos & $8,69 \%$ \\
\hline & Consultariam médico responsável & $13,40 \%$ \\
\hline & $\begin{array}{l}\text { Tratamento paliativo para controlar } \\
\text { sintomas }\end{array}$ & $4,34 \%$ \\
\hline
\end{tabular}

Para aliviar a sensação de xerostomia, a maioria dos participantes responderam que utilizam saliva artificial em seus pacientes (Tabela 6). 
Tabela 6 - Respostas a respeito do tratamento da xerostomia

\begin{tabular}{l|r}
\hline \multicolumn{2}{l}{$\begin{array}{l}\text { Para aliviar a sensação de xerostomia, que medida você } \\
\text { adotaria? }\end{array}$} \\
\hline Não responderam & $21,73 \%$ \\
Ingestão frequente de água & $39,13 \%$ \\
Mastigar chicletes ou balas sem açúcar & $26,08 \%$ \\
Saliva artificial & $52,17 \%$ \\
Massagem estimulante nas glândulas salivares & $4,34 \%$ \\
Enxaguatórios bucais & $4,34 \%$ \\
Chá de camomila com uma colher de chá de & $28,69 \%$ \\
bicarbonato de sódio & $4,34 \%$ \\
Flúor tópico & $4,34 \%$ \\
Sialogogos
\end{tabular}

Fonte: elaboração dos autores.

Dos entrevistados, $43,47 \%$ não saberiam fazer o diagnóstico de mucosite. Quanto ao tratamento da mucosite, as respostas mais relevantes foram a utilização de corticoides e a laserterapia, porém, a maior parte $(21,7 \%)$ dos entrevistados não responderam essa questão (Tabela 7).

Tabela 7 -Respostas referentes ao diagnóstico e ao tratamento da mucosite

\begin{tabular}{|c|c|c|}
\hline \multicolumn{3}{|c|}{ Mucosite } \\
\hline \multirow{3}{*}{$\begin{array}{l}\text { Saberia fazer } \\
\text { o correto } \\
\text { diagnóstico? }\end{array}$} & Sim & $39,13 \%$ \\
\hline & Não & $43,47 \%$ \\
\hline & Não responderam & $17,39 \%$ \\
\hline \multirow{18}{*}{$\begin{array}{l}\text { Qual } \\
\text { tratamento } \\
\text { adotaria? }\end{array}$} & Não responderam & $21,73 \%$ \\
\hline & Corticoides & $13,04 \%$ \\
\hline & Antifúngico & $8,69 \%$ \\
\hline & Profilaxia & $4,34 \%$ \\
\hline & Encaminhariam para patologista & $8,69 \%$ \\
\hline & $\begin{array}{l}\text { Encaminhariam para } \\
\text { estomatologista }\end{array}$ & $8,69 \%$ \\
\hline & $\begin{array}{l}\text { Encaminhariam para } \\
\text { bucomaxilofacial }\end{array}$ & $4,34 \%$ \\
\hline & Antibiótico & $4,34 \%$ \\
\hline & Bochechos com flúor & $4,34 \%$ \\
\hline & Bochechos com solução salina & $4,34 \%$ \\
\hline & Bochechos com chá de camomila & $4,34 \%$ \\
\hline & Clorexidina & $8,69 \%$ \\
\hline & Laserterapia & $13,04 \%$ \\
\hline & Anestésico & $8,69 \%$ \\
\hline & Cuidado com higiene & $13,04 \%$ \\
\hline & Anti-inflamatório & $13,04 \%$ \\
\hline & Analgésico & $13,04 \%$ \\
\hline & $\begin{array}{l}\text { Evitar alimentos quentes, duros, } \\
\text { apimentados, ácidos e cítricos }\end{array}$ & $4,34 \%$ \\
\hline
\end{tabular}

Fonte: elaboração dos autores.

Para a realização de procedimentos odontológicos durante o tratamento oncológico, a maioria dos profissionais pediriam a avaliação médica (Tabela 8).
Tabela 8 - Restrições aos tratamentos odontológicos

Em que situação(ões), nos pacientes oncológicos, você evitaria realizar um procedimento odontológico?

\begin{tabular}{l|r}
\hline Não responderam & $17,39 \%$ \\
Paciente debilitado, com baixa imunidade & $21,73 \%$ \\
Pacientes submetidos à quimioterapia e à & $4,34 \%$ \\
radioterapia recentemente & $21,73 \%$ \\
Procedimentos invasivos & $8,69 \%$ \\
Atenderiam apenas em situação de urgência & $26,08 \%$ \\
\hline Pacientes em tratamento, pediriam avaliação &
\end{tabular}
médica

Fonte: elaboração dos autores.

A xerostomia foi a complicação bucal mais apontada entre os problemas que os pacientes submetidos à quimioterapia, à radioterapia ou a transplante de medula óssea podem apresentar. As infecções também foram bastante citadas (Tabela 9).

Tabela 9 - Complicações bucais que os pacientes em tratamento quimioterápico/radioterápico podem apresentar

\begin{tabular}{l|r}
\hline \multicolumn{2}{l}{ Complicações citadas pelos cirurgiões-dentistas entrevistados } \\
\hline Xerostomia & $30,43 \%$ \\
Infecções & $21,73 \%$ \\
Doença periodontal & $17,39 \%$ \\
Mucosite & $13,04 \%$ \\
Cáries & $13,04 \%$ \\
Osteorradionecrose & $13,04 \%$ \\
Feridas na boca & $8,69 \%$ \\
Baixa imunidade/ debilidade física & $8,69 \%$ \\
Sequestros ósseos & $4,34 \%$ \\
Perda do paladar & $4,34 \%$ \\
Sensibilidade & $4,34 \%$ \\
Lesão eritematosa & 4,34 \\
Restaurações caem sem motivo e endodontia & 4,34 \\
sem melhora, refluxo e hiperceratose jugal & $13,04 \%$ \\
Não responderam & \\
\hline Fonte: elaboração dos autores. &
\end{tabular}

Por fim, sobre qual protocolo é seguido pelo dentista para que as alterações ocasionadas nos pacientes oncológicos possam ser diagnosticadas precocemente, os sujeitos responderam que é necessário verificar as condições bucais do paciente antes do início do tratamento radioterápico. Além disso, entrar em contato com o médico responsável para saber se é possível realizar qualquer procedimento, quais medicamentos podem ser indicados, e para tirar dúvidas a respeito do estado de saúde geral do paciente.

\section{Discussão}

Os pacientes submetidos à quimioterapia e/ou à radioterapia podem apresentar complicações na cavidade bucal. No momento da consulta, o médico deve explicar ao paciente a necessidade de um 
acompanhamento odontológico durante o tratamento contra o câncer.

Assim como nesta pesquisa, outros estudos mostram que a clorexidina é o antisséptico bucal mais indicado para pacientes durante o tratamento oncológico $^{1,5,10}$. Isso porque a clorexidina apresenta baixa toxicidade, possui uma tendência em suavizar os sintomas dolorosos durante a radioterapia, promove uma limpeza mecânica da boca, agindo nos tecidos necróticos ${ }^{15}$, e impede o crescimento de $S$. mutans ${ }^{16}$. A clorexidina apresenta uma substantividade, isto é, tempo de permanência ativa de aproximadamente 12 horas, exercendo uma ação bactericida inicial, imediatamente após o bochecho, combinada com uma ação bacteriostática prolongada ${ }^{17}$. Além disso, sua formulação em veículo aquoso, sem álcool ou conservantes, pode diminuir o desconforto durante o seu uso sem perda da eficácia ${ }^{18}$.

$\mathrm{Na}$ presença de terceiros molares impactados, não são indicadas as exodontias, o que vai ao encontro dos resultados da pesquisa ${ }^{10}$. Porém, dentes parcialmente erupcionados devem ser removidos, para prevenir infecção pericoronária, no entanto, na pesquisa, 78,26\% dos dentistas não fariam a exodontia de dentes parcialmente erupcionados ${ }^{1,10}$. Algumas manifestações bucais são comuns após o término da quimioterapia ou radioterapia, portanto, devem ser feitas consultas de manutenção a cada 3 ou 4 meses, o que foi confirmado no estudo. Para colocação de implantes, devem ser avaliados alguns critérios, como tipo de radiação, dose, locais e a fisiologia própria do paciente ${ }^{10}$.

O tempo para ocorrer a osseointegração é mais prolongado em pacientes irradiados devido à menor atividade metabólica no osso. O paciente deve ser orientado quanto à higienização bucal, já que seus tecidos não serão mais tão capazes de resistir à invasão bacteriana ${ }^{10}$. A maioria dos dentistas, neste estudo, relataram que não indicariam a colocação de implantes após a terapia radioterápica. As exodontias devem ser realizadas, preferencialmente, antes do tratamento oncológico, pois o tecido irradiado torna-se hipovascularizado, hipocelular e hipóxico, comprometendo a cicatrização e não permitindo a formação de tecido de granulação ${ }^{19}$.

Os riscos de ocorrência da osteorradionecrose continuam após a terapia de irradiação, sendo assim, as exodontias devem ser realizadas, pelo menos, um ano após a conclusão do tratamento, o que condiz com o trabalho. Atualmente, há um aprimoramento dos protocolos de tratamento e, principalmente, de medidas de prevenção e melhora das técnicas de radioterapia ${ }^{20}$. Entretanto, é necessário avaliar caso a caso, pois a falta de envolvimento do paciente na manutenção da higidez bucal pode aumentar o risco de desenvolvimento de osteorradionecrose ${ }^{21}$. Recomenda-se a utilização de técnicas atraumáticas e o uso de oxigênio hiperbárico antes e após a exodontia, o que aumenta a oxigenação tecidual local e o crescimento intratecidual em hipóxia ${ }^{10}$.
Quanto às próteses, pacientes que se tornaram edêntulos pouco antes ou logo após a radioterapia estão mais propensos a ter problemas como ulcerações de mucosa. Deve ser feito o acompanhamento regular das próteses para a realização de ajustes em áreas que possam causar rompimento da mucosa e exposição óssea ${ }^{10,13}$. As próteses totais podem ser utilizadas contanto que sejam removidas à noite. As próteses parciais devem estar sem aspereza e sem ponto de pressão, o que também foi descrito pelos cirurgiões-dentistas no questionário ${ }^{22}$.

Em relação ao tratamento das infecções fúngicas, as medicações mais indicadas para cândida são o Clotrimazol e a Nistatina. Nos casos mais resistentes, o Cetoconazol ou o Fluconazol podem ser prescritos ${ }^{10,23-27}$. A Nistatina foi mais relatada na pesquisa, provavelmente, por ser o antifúngico mais conhecido entre os dentistas, já que se caracteriza por um baixo custo e está disponível na rede pública.

Nas infecções virais, o tratamento é paliativo, podendo ser utilizada a administração profilática de Aciclovir, com função preventiva ${ }^{24}$. Sobre essa questão, grande parte dos participantes não responderam, porém, dentre os que responderam, o Aciclovir foi o medicamento mais utilizado.

Para aliviar a sensação de xerostomia podem ser empregados sialogogos, que são capazes de estimular as glândulas funcionais restantes ${ }^{23,24,26-29}$. $\mathrm{O}$ uso de chicletes sem açúcar com o intuito de aumentar a produção de saliva é um dos métodos mais empregados, desde que haja alguma saliva sendo produzida $^{10}$. Muitos pacientes, mesmo com o término do tratamento oncológico, não têm uma melhora do fluxo salivar, sendo necessária a reposição exógena de saliva, como a ingestão de água aos poucos durante o dia ${ }^{5,10}$. A solução salina $0,9 \%$ ou a solução de bicarbonato também podem ser utilizadas para aliviar os sintomas, assim como a saliva artificial ${ }^{1}$. Os tratamentos encontrados na literatura também foram relacionados no questionário, sendo a saliva artificial o mais indicado.

A maioria dos pesquisados relataram não saber fazer o correto diagnóstico de mucosite, o que está de acordo com os achados bibliográficos, pois ainda não se encontra um consenso quanto ao melhor tratamento para a mucosite ${ }^{9,23}$. Podem ser feitos bochechos com bicarbonato de sódio ou solução de soro fisiológico a $0,9 \%$. Se o paciente relatar dor, são recomendados bochechos com anestésico ou analgésico, também podem ser indicados clorexidina $0,12 \%$, anti-inflamatórios e laserterapia, o que também é indicado nas respostas do questionário ${ }^{19}$. Entre os resultados, foi apresentada, ainda, a utilização de antifúngicos, corticoides, bochechos com chá de camomila e antibióticos, o que também foi encontrado na literatura ${ }^{1,30,31}$

Todos os procedimentos odontológicos deveriam ser realizados antes de iniciar a quimioterapia ou radioterapia, a fim de evitar complicações bucais ${ }^{3}$. 
Deve também ser evitada a realização de tratamentos invasivos, pelo menos, um ano após o tratamento radioterápico, com o intuito de evitar a osteorradionecrose $^{31}$, estando de acordo com os resultados da pesquisa. Porém, nessa questão, a maioria dos dentistas responderam que pediriam uma avaliação médica antes de realizar qualquer procedimento odontológico, provavelmente com o intuito de obter uma visão multidisciplinar sobre a condição sistêmica do paciente.

As manifestações bucais mais frequentes em pacientes que estão em tratamento oncológico são mucosite, xerostomia, infecções fúngicas e virais, osteorradionecrose, limitação do grau de abertura bucal (trismo), periodontite, diminuição da qualidade da função mastigatória, disgeusia e cárie de radiação $0^{1-8}$. A maioria dessas manifestações foram citadas pelos cirurgiões-dentistas.

É de fundamental importância o conhecimento do cirurgião-dentista sobre o assunto, para que ele possa realizar a prevenção e o tratamento das complicações caso existam, amenizando o desconforto do paciente e melhorando sua condição de vida.

\section{Conclusão}

Com base nos dados coletados neste estudo, pode-se concluir que os cirurgiões-dentistas pesquisados apresentam conhecimento para minimizar os efeitos secundários do tratamento oncológico. As dúvidas existentes em relação a algumas questões podem ser justificadas pelo fato de esses profissionais não serem especialistas na área.

\section{Abstract}

Objective: to evaluate, through a questionnaire, the level of knowledge of dentists on the care for cancer patients. Subjects and method: 51 questionnaires were distributed in the city of Capão da Canoa, RS, Brazil, and 23 of them were answered. Results: most professionals use $0.12 \%$ chlorhexidine as mouthwash during the care for patients undergoing chemotherapy and/or radiotherapy, and these professionals would not extract the third molars and partially erupted teeth of these patients. $52.17 \%$ would not indicate installing implants after radiotherapy, and the remaining respondents would do it after 1 year at least. To perform extractions and avoid osteoradionecrosis, $21.73 \%$ of professionals would do it only after 6 months, 39.13\% after 1 year, and the remaining would do it after 3 years or more. For yeast infections, the most indicated drug was Nystatin. In the case of viral infections, most did not respond. $43.47 \%$ of respondents would not know how to diagnose mucositis, and most of them did not respond regarding its treatment. Xerostomia was the oral complication most often mentioned among the problems these patients may present; infections were also mentioned. For the early diagnosis of these changes and for knowing how to act during the treatment of cancer patients, the respondents answered that it is necessary to verify the oral condition of patients before starting radiotherapy and to contact the physician in charge to learn about the general health status of the patient. Conclusion: several dentists still have doubts about the care for cancer patients, not knowing how to perform a protocol to care of these patients.

Keywords: Surveys and questionnaires. Neoplasms. Dentistry. Oncology.

\section{Referências}

1. Grimaldi N, Sarmento V, Provedel L, Almeida D, Cunha S. Conduta do cirurgião-dentista na prevenção e tratamento da osteorradionecrose: revisão de literatura. Rev Bras de Cancerologia 2005; 51(4):319-24.

2. Kelner N, Castro JFL. Laser de baixa intensidade no tratamento da mucosite oral induzida pela radioterapia: relato de casos clínicos. Rev Bras Cancerologia 2007; 53(1):29-33.

3. Jbam BC, Freire ARS. Complicações bucais da radioterapia em cabeça e pescoço. Rev Bras Otorrinolaringol 2006; 72(5):704-8.

4. Pelisser A, Vier-Pelisser FV, Fontanella VRC, Figueiredo MAZ. Análise microscópica do efeito da radioterapia fracionada por cobalto-60 em mandíbula de rato. Radiol Bras 2007; 40(2):113-8.

5. Santos ACM, Noguti F, Mendes FCA, Alborghetti GP, Pereira MB. Complicações bucais no tratamento radioterápico. [citado 13 out. 2012]. Disponível em URL: http://www.dracarolinafernandes.com.br/dicas/oncologialaserterapia/complicacao.pdf.

6. Segreto HRC, Segreto RA. Revisão e atualização em radiobiologia. Aspectos celulares, moleculares e clínicos. A Folha Médica 2000; 119:9-27.

7. Vier FV, Cherubini K, Figueiredo MAZ, Yurgel LS. Manejo da osteorradionecrose em pacientes submetidos à radioterapia de cabeça e pescoço. Rev Odonto Ciência 2005; 20(47):23-8.

8. Vissink A, Jansma J, Spijkervet FK, Burlage FR, Coppes RP. Oral sequelae of head and neck radiotherapy. Crit Rev Oral Biol Med 2003; 14:199-212.

9. Costa RCL, Costa EL, Costa JF, Neves MIR, Silva NB. Manifestações bucais em pacientes infanto-juvenis submetidos a tratamento antineoplásico: Revisão de Literatura. NewsLab $2007 ; 84: 130-42$.

10. Hupp JR, Ellis III E, Tucker MR. Cirurgia oral e maxilofacial contemporânea. 5. ed. Rio de Janeiro: Elsevier; 2009.

11. Pozzobon JL, Ortiz FR, Braun K, Unfer B. Complicações bucais dos tratamentos de câncer de cabeça e pescoço e de malignidades hematológicas. RFO UPF 2011; 16(3):342-6.

12. Ragghianti MS, Greghi SLA, Capelozza ALA, Resende DRB Tratamento radioterápico: Parte II - Estratégias de atendimento clínico. Salusvita 2002; 21(1):87-96.

13. Silva LCF, Paulinelli MN, Meira RA. Avaliação dos fatores de risco dentais e de malignidade em radioterapia da cabeça e do pescoço. Rev Cirurgia Traumatol Buco-Maxilo-Facial 2004; 4(3):187-95.

14. Almeida FCS, Vaccarezza GF, Cazal C, Benedethe AP, Pinto Jr. D, Tavares MR, et al. Avaliação odontológica de pacientes com câncer de boca pré e pós tratamento oncológico - uma proposta de protocolo. Pesq Bras Odontoped Clin Integr 2004; 4(1):25-31.

15. Labbate R, Lehn CN, Denardin OVP. Efeito da clorexidina na mucosite induzida por radioterapia em câncer de cabeça $e$ pescoço. Rev Bras Otorrinolaringol 2003; 69(3):349-54. 
16. Antonio AMMP, Maia FAZ, Dias RB. Reações adversas da radioterapia: cuidados pré, trans e pós operatório. Rev Odonto 2001; 9:12-9.

17. Zanatta FB, Rosing CK. Clorexidina: mecanismo de ação e evidências atuais de sua eficácia no contexto do biofilme supragengival. Scientific 2007; 1(2):35-43.

18. Olsson H, Asklow B, Johansson E, Slote C. Rinsing with alcohol-free or alcohol-based chlorhexidine solutions after periodontal surgery. A double-blind, randomized, cross-over, pilot study. Sweed Dent J 2012; 36(2):91-9.

19. Silva MC, Iwaki LCV, Valentin L, Inagaki LE, Candido GC. Protocolo clínico e estratégias adotadas no Projeto Vida (câncer bucal) da Universidade Estadual de Maringá. Rev Bras Odontol 2008; 65(1):135-41.

20. Guimarães Jr J. Tratamento das manifestações estomatológicas antes, no decorrer e depois de quimio e radioterapia. In: Marcucci G (ed.). Fundamentos de Odontologia - Estomatologia. Rio de Janeiro: Guanabara Koogan; 2005. p. 205-11.

21. Curi MM, Dib LL. Osteoradionecrosis of the jaws: a retrospective study of the background factors and treatment in 104 cases. J Oral Maxillofac Surg 1997; 55(6):540-4; discussion 545-6.

22. Santos MG, Silva LCF, Lins CA, Passos DD, Oliveira Neto JN, Santos TS. Fatores de risco em radioterapia de cabeça e pescoço. RGO - Rev Gaúcha Odontol 2010; 58(2):191-6.

23. Rolim AEH, Costa LJ, Ramalho LMP. Repercussões da radioterapia na região orofacial e seu tratamento. Radiol Bras 2011; 44(6):388-95.

24. Albuquerque RA, Morais VLL, Sobral APV. Protocolo de atendimento odontológico a pacientes oncológicos pediátricos - revisão de literatura. Rev Odontol da Unesp 2007; 36(3):275-80.

25. Hespanhol FL. Levantamento epidemiológico de manifestações bucais em pacientes submetidos à quimioterapia [Dissertação de mestrado]. Duque de Caxias: Curso de Odontologia da Universidade do Grande Rio; 2007.

26. Marinho TG, Júnior BAS, Gonçalves SRJ, Júnior RLCA, Dos Anjos Neto DA, et al. Complicações da radioterapia de cabeça e pescoço: revisão de literatura. Cadernos de Graduação - Ciências Biológicas e da Saúde 2011; 13(13):81-7.

27. Salazar M, Victorino FR, Paranhos LR, Ricci ID, Gaeti WP, Caçador NP. Efeitos e tratamento da radioterapia de cabeça de interesse ao cirurgião-dentista - Revisão de Literatura. Revista Odonto 2008; 16(31):62-8.

28. Ramos FMM, Terra ER, Brayner SC, Neto FH, Bóscolo FN. $\mathrm{O}$ papel do cirurgião-dentista na radioterapia de cabeça e pescoço. Odontologia Clín Científ 2005; 4(2):89-94.

29. Tommasi AF. Diagnóstico em patologia bucal. 3. ed. São Paulo: Pancast; 2002.

30. Martins D, Martins MA, Sêneda LM. Suporte odontológico ao paciente oncológico: prevenção, diagnóstico, tratamento e reabilitação das sequelas bucais. Prat Hosp 2005; 7(41):166-9.

31. Neville BW, Damm DD, Allen CM, Bouquot JE. Patologia oral e maxilofacial. 3. ed. Rio de Janeiro: Elsevier; 2009.

\section{Endereço para correspondência:}

Marcylene Arruda Braz

Oswaldo Aranha, 651

Torres, RS

Fone: (51) 9857303

E-mail:marcy.braz@hotmail.com

Recebido: 07/10/2016. Aceito: 07/03/2017. 